\title{
Utilization of Proteinic Biopolymers: Current Status and Future Prospects
}

S. Mowafi, M. Abou Taleb, and H. El-Sayed

Proteinic and Man-made Fibres Department, Textile Industries Research Division, National Research Centre, 33 El-Buhouth St., 12622-Dokki, Giza, Egypt

\begin{abstract}
W ITHIN the last three decades, environmental pollution has increased the interest of the researchers to find new health and hygiene-related products for mankind. In the textile industry, utilization of low-environmental impact technologies that based on sustainable biopolymers, presents a novel possible way for development of bioactive textiles on a large scale. The purpose of this review is to introduce a general overview on the role of proteinic biopolymers in development of textile industries. Unconventional non-textile applications of these biopolymers are also outlined. The methods of extraction of proteinic biopolymers from their renewable natural resources were discussed to assign the proper method of extraction.
\end{abstract}

Keywords: biopolymer, protein, extraction, utilization, textile

\section{Introduction}

\section{Definition}

Biopolymers are defined as macromolecules completely or partially produced in a normal way by living organisms [1]. The prefix "bio" means that they are produced by living organisms and thus are biodegradable.
Several names are used to refer to this environmentally friendly polymers e.g. "Green Polymers", "environmentally degradable polymers" or "bio-based polymers" [2]; nowadays biopolymers are commonly worldwide used and applied, see Figure 1.

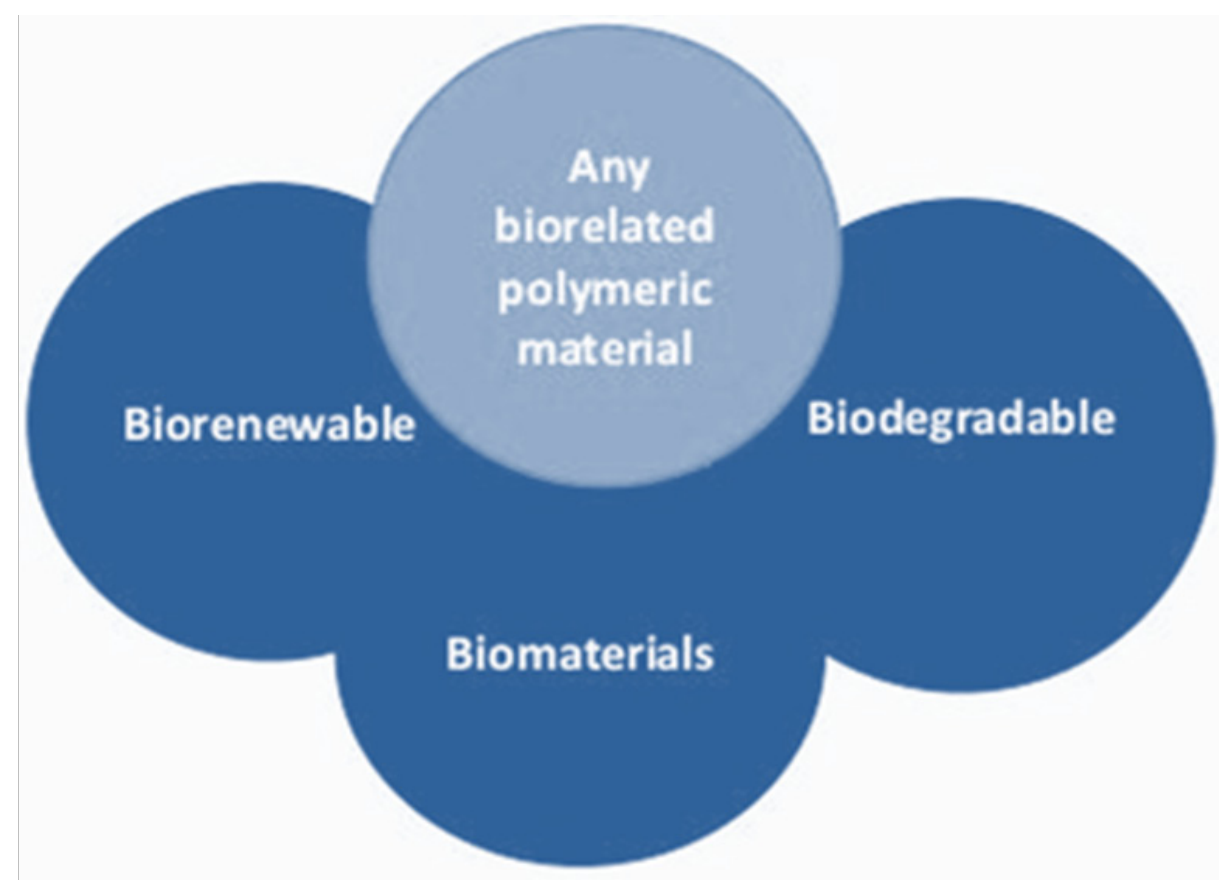

Fig. 1. Nature of Biopolymer .

*Corresponding author : ibrahimesalwa82@yahoo.com

DOI: 10.21608/JTCPS.2018.5007.1002

C2018 National Information and Documentation Centre (NIDOC) 
Biopolymers are polymers that contain monomeric units which are covalently bonded to form large structure as shown in figure 2 . Biopolymer does not cause problems to the environment comparing with the synthetic polymers because the biopolymers are easy to degrade by micro-organisms in the environment into carbon dioxide and water [3].

The high resistance of synthetic polymer to biological degradation leads to their accumulation in nature and landfills, so the biodegradable polymeric materials are promising alternatives to man-made polymers [4].

\section{Classification of Biopolymer}

Figure 3 shows the classification of biopolymers and their origin, which generally classified into two main categories:

(i) Synthetic origin biopolymers: polymers that are synthesized chemically but are derived from biological starting materials such as sugars, amino acids, and natural fats or oils, so they may be mentioned as synthetic natural product-based polymer [5].

(ii)Natural origin biopolymers: polymers that are obtained by living organisms, plants and animals.

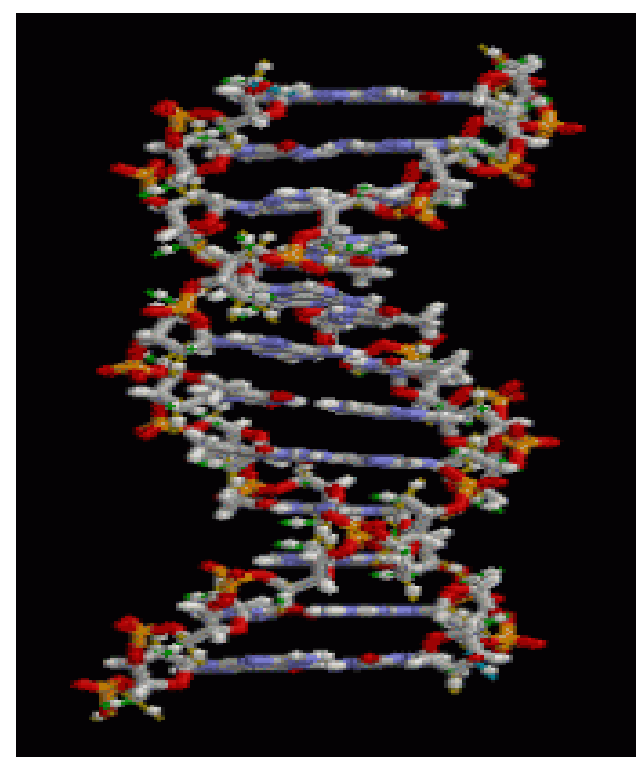

Fig. 2. 3-D Structure of a Biopolymer .

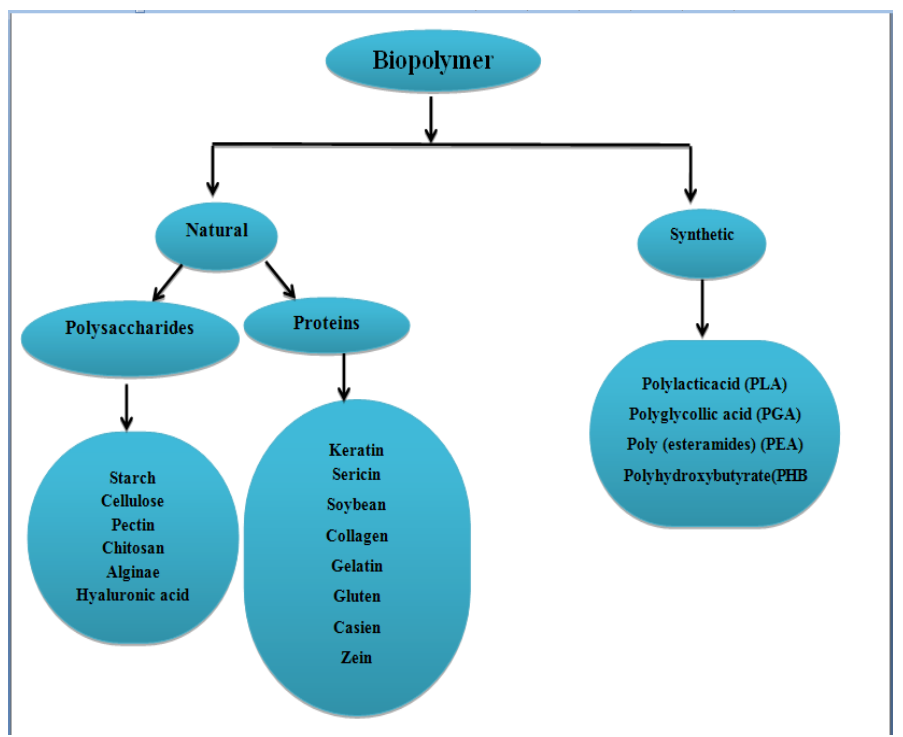

Fig. 3. Classification of Biopolymers and their Origin. 


\section{Biopolymers Market Worldwide}

Due to their environment friendly properties, biopolymers are now important for every area including food technology, nanotech, chemistry, textile, medical, agriculture etc [6]. According to market research, consumers are willing to pay more for bio-based polymers, and their market shows huge growth; reached to 3 million tons per year by 2013 [7] and it is expected to reached to 7 million tons by 2018 (see Figure 4).

In this review, the chemistry and application of proteinic biopolymer in textile sector was highlighted.

\section{Chemistry of Proteinic Biopolymer}

Proteins, or polypeptides, are the essential form of biomacromolecules that are characteristic for all living systems. Proteins are polymers that are consist of up to 20 different amino acids building blocks linked by peptide bonds. Proteins may contain a few hundred or thousands amino acid units as shown in Figure 5, which illustrates the different structures of protiens.

The linear sequence is known as primary structure, the three-dimensional arrangements of the backbone refers to the secondary structure, the attraction between alpha helix and pleated sheet resulted the tertiary structure which is the structure of an entire protein; and the quaternary structure describes the structure of proteins that containing more than one polypeptide chain [8].

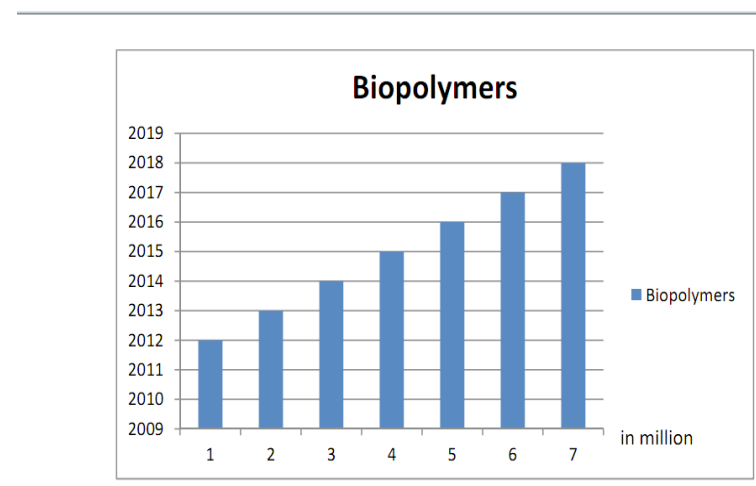

Fig. 4.The Production of Biopolymers per Year.
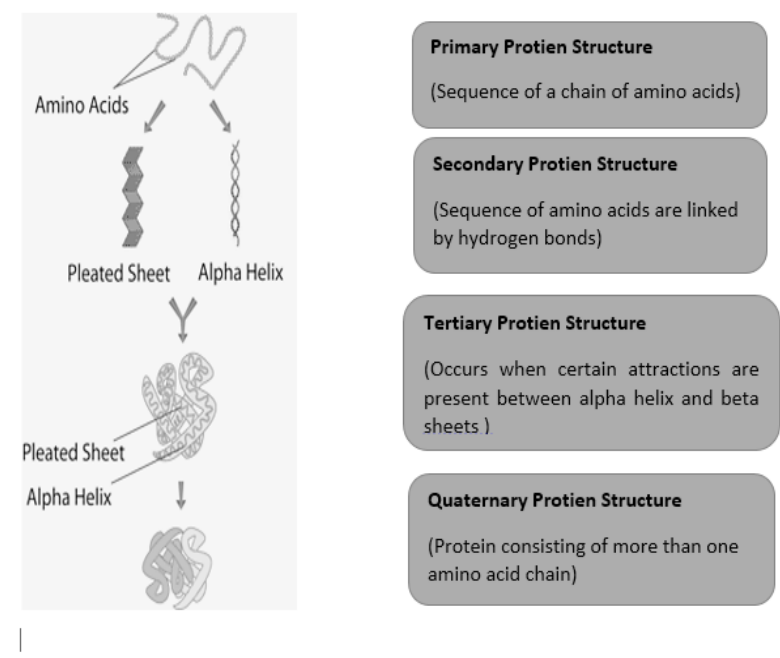

Fig.5. Different Structures of Proteins. 
In terms of waste proteins, there are various kinds that are collected in large amounts: namely keratin from wool industry, poultry feathers, hair, nails, beaks, hooves, claws, and horns, sericin from degumming of silk, casein from skimmed milk, zein as a byproduct from corn starch production, wheat gluten (WG) the main protein of wheat, collagen or gelatin from meat industry byproducts, and soybean protien after oil extraction [9].

\section{Keratin}

Keratin is considered as one of the most abundant proteinic biopolymers in the world[10]; it is mainly present in epithelial cells in higher vertebrates[11].Keratin has $90 \%$ of proteins, $2-5 \%$ sulphur, $15-18 \%$ nitrogen, 3.2\% mineral elements and $1.27 \%$ fat. The essential amino acids in keratin are cysteine, glycine, proline, serine and low content of lysine, histidine and methionine.

Keratin found in different forms including $\alpha$, $\beta$, and $\gamma$-keratins. $\alpha$ - keratins or soft keratins are low in sulphur content and usually found in the soft tissues including sheep wool, skin, and hair. $\beta$ - Keratins or hard keratins are rich in sulphur content and usually present in the hard tissues such as bird feather, horns, claws, nails, and hooves [12]. $\gamma$ - Keratins are globular associated with $\alpha$ and $\beta$ sheets and have a high content of cysteine. Keratin polypeptide chains are highly cross-linked by disulphide bonds, hydrophobic interactions and hydrogen bonding.

\section{Sericin}

Sericin is amorphous and globular protein and constitutes 25 to 30 percent of the silk proteins. Sericin is an extremely hydrophilic macromolecular protein containing of 18 amino acids with major amino acid groups namely; serine $(40 \%)$, glycine $(16 \%)$, glutamic acid, aspartic acid, threonine, tyrosine. Thus, sericin consists of polar side chain made of about $42.3 \%$ hydroxyl, carboxyl and amino groups.

Sericin of cocoon shell has been classified into two classes: $\alpha$-sericin (the outer cocoon shell) and $\beta$-sericin (inner layer).In another study, sericin may also be divided into three classes: sericin A, sericin B, and sericin C. Sericin A is outermost layer in silk and it is insoluble in water, sericin B is the middle layer and sericin $\mathrm{C}$ is the innermost layer and is insoluble in hot water. The innermost layer is adjacent to fibroin and can be removed from fibroin by treatment with hot dilute acid or alkali [13].

\section{Casein}

Caseins are phosphoproteins that precipitate from raw milk via acidification to $\mathrm{pH} 4.6$ at $20^{\circ} \mathrm{C}$ [14].Caseins are conjugated proteins, mostly with phosphate group(s) esterified to serine residues. Generally, caseins have limited $\alpha$-helix and $\beta$-sheet secondary structure, caseins exhibit high number of proline and no disulfide bonds.

\section{Collagen}

Collagen (fibrous protein) is a proteinic biopolymer mostly composed of a repeated tripeptide (proline, hydroxyproline and glycine) that provides the tendency of forming a triple helix by twisting of three strands [15].

\section{Gelatin}

Gelatin is a natural biopolymer that is prepared by partial hydrolysis of collagens. Gelatin contains 18 different amino acids, mainly is glycine (almost 1 glycine residue arranged every third residue), proline and 4-hydroxyproline residues. A typical structure is (-Ala-Gly-Pro-Arg-Gly-Glu-4HypGly-Pro-) [16].

\section{Soybean}

Soybean is a protein that obtained subsequently beans being pressed and oil is removed. Soybeans are very reach with proteins (about $37-42 \%$ of dry bean) that contain 18 different amino acids [17]. There are about $23 \%$ of acidic amino acids (glutamic acid and aspartic amino acid), about $25 \%$ of alkaline amino acids (serine, arginine, lysine, tyrosine, threonine, tryptophan) and about $30 \%$ of neutral amino acids (leucine, phenylalanine, valine, alanine, isoleucine, proline, glycine). Sulphur-containing amino acids are also present in soy proteins in about $1.0 \%$ of cysteine and $0.35 \%$ of methionine.

\section{Gluten}

Wheat gluten (WG) is produced by washing of wheat with water until all the starch granules are removed. WG is composed of a mixture of complex protein molecules in equal quantities; namely glutenins and gliadins [18]. Gliadins and glutenins are high in both glutamine and proline and also have a considerable number of nonpolar amino acids, containing aliphatic or aromatic groups which responsible for the insolubility of gluten in water.

\section{Zein}

Zein, plant protein, performs around $80 \%$ of the whole protein content in corn. Zein has an elongated globular shape and possesses nearly 
50\%hydrophobic amino acid residues, including high percentages of leucine (20\%), proline $(10 \%)$ and alanine $(10 \%)$, however zein has a relatively high content $(21 \%-26 \%)$ of glutamine (hydrophilic amino acid). Based on the differences in solubility and molar mass, zein is classified into three different fracti ons called $\alpha$-, $\beta$ - and $\gamma$-zein [19]. The $\alpha$-zein fraction is obtained in greater amounts in the commercial extraction process. Approximately $80 \%$ of the total prolamine present in corn, while the $\beta$ - and $\gamma$-zein fractions are only $10-15 \%$ and $5-10 \%$, respectively.

Due to the interest in biopolymers as a substituent for the commercially aggressive chemicals in textile industry, research on protienaceous material has remarkably increased.

Recent Utilization of Proteinic Biopolymer in Textile Sector

Recently, biopolymers boast greater environmental consciousness than most modern technologies, thus they have been utilized in several industries and products lines such as textiles, packaging, fast food container and packaging, lawn and garden waste bags, paper coating, agriculture mulch films, toys, tubes, medical products, disposable wipes, erosion control, biologically based resins, car parts, glass fibers agents, as well as adhesives and coatings [20].

\section{Utilization of proteinic biopolymer in high performance textiles}

Several studies were carried out to enhance the performance attributes of textile goods through finishing by proteinic biopolymers.

\section{Keratin}

The estimated quantity of keratin wastes, which are abundantly available as a byproduct from several industries, including wool from textile industry, horns and hooves from slaughterhouse, feathers from poultry cultivation, human hair, animals and hair from tanneries, amounts more than 4 million tons per year into the environment [21]. It is noteworthy to mention that about 25 million tons of animal byproducts are generated worldwide per annum [22].

Due to the large amounts of keratin wastes that cause the environmental pollution, many studies focused on the reconversion of keratin based waste biomass into commercially used product. Beside the application of keratin in cosmetic and pharmaceutical products, it has been utilized in textile processing.
Functionalization of textile materials by keratin

Water-soluble keratin hydrolysate was applied to improve the shrinking resistance of wool fabrics. Addition of silver nanoparticle to wool together with keratin improved the fabrics dimensional stability with imparting antimicrobial efficacy [23].

In another study, superheated water was used to prepare keratin solution from wool wastes industry and then wool fabrics were treated with that prepared keratin solution to provide antifelting properties [24].

Recently, an innovative wool dissolving system based on sodium bisulphite and ozone was prepared and employed to improve anti-pilling of cashmere fabric [25].

In order to reduce the environmental impact of poly vinyl alcohol (PVA) as a sizing agent for synthetic fibers and blends, keratin from chicken feathers was used as warp sizing agents on polyester/cotton blends and polyester, the results of this investigation showed that by comparing with (PVA), treatment by the obtained chicken feathers keratin provided sizing behavior with improving the tensile strength and abrasion resistance for the polyester/cotton blends and polyester yarns [26].

In a recent project at the National Research Centre in Egypt, keratin was applied onto the surface of nonwoven fabrics made up of polyamide, acrylic, polyester, and viscose fabrics by electrospinning technique. The said modified fabrics were then utilized in purification of selected industrial waste water from heavy metal ions or other pollutants [27].

\section{Sericin}

Sericin exhibits many unique properties such as biocompatibility, biodegradability, antibiotic-antibacterial activity, UV resistant, and moisture absorption ability [28]. Therefore, sericin has become an attractive product for its versatile applications in different fields including; pharmaceuticals, cosmetics, food industry and textiles.

Sericin consists of several polar side chains, about $42.3 \%$, including hydroxyl, carboxyl and amino groups, so it has been applied for finishing of the natural and man-made textiles. 


\section{Treatment of natural fibers by sericin}

Due to its chemical composition, sericin has adhesive property and affinity to wool keratin [29]. It has been reported that, sericin was grafted into wool fiber to improve fiber strength, shrinkage resistance, and softness [30].

In a similar study, sericin was applied as a finishing agent for wool fabrics to improve the fabrics touch, absorption of water (wettability) as well as antibacterial activity [31].

Moreover, in our division, sericin biopolymer was applied in feltproofing of wool fibers [32]. Whereas the susceptibility of wool to sericin was enhanced by creation of new active sites along the wool keratin molecules, such as cysteic acid and S-cystine sulphonate residues, by pretreatment with hydrogen peroxide and sodium sulphite.

In another research, cotton fabrics were modified by silk sericin to improve its properties. Sericin was applied in presence of different crosslinking agents to improve moisture regain, water retention and decreased electrical conductivity of cotton fibers to get more comfortable finished fabric to wear $[33,34]$.

Furthermore, silk sericin was applied as an antibacterial finishing agent onto cotton fabrics where the sericin-coated cotton fabric showed a high degree of bacterial activity against $\mathrm{S}$. aureus and E. coli [35].

Cotton fabric was also treated by sericin/ nano- $\mathrm{TiO}_{2}$ composite in presence or absence of polycarboxylic acid as crosslinking agent using pad-dry-cure to enhance the antibacterial properties without influence on the breaking strength of the treated fabrics [36]

In a novel strategy to fabricate multi-functional cotton textiles, silver nanoparticles-sericin (Ag NPs-sericin) hybrid colloid was prepared using sericin as reducing agent and dispersing agent. This approach showed cotton fabrics not only possessed excellent antibacterial activity, but also it has smooth handle and good moisture absorption owing to sericin protein coated on the fabrics [37].

\section{Treatment of synthetic fibers}

It has been reported by many workers that sericin can be used for treatment of polyester fabrics to impart certain desired properties, such as enhanced hygroscopicity, UV protection, antistatic properties, and bacterial resistance [38].
Sericin was applied on polyamide or polyester fibers to obtain antioxidant and antimicrobial activity that able to be used as indoor air filters to decrease free radicals and fungi or bacteria contaminations [39].

In another approach, sericin was anchored onto ethylene diamine-pretreated polyester fabric along with chloromethyloxirane or cyanuric chloride, as a cross-linking agent to improve the moisture absorption ability with increased harshness of the polyester fabrics [40]. Different crosslinking agents such as formaldehyde and glutaraldehyde were studied for fixation of sericin on polyester [41].

Gupta et al reported that sericin-coated polyester fabric using glutaraldehyde as crosslinking agent showed an improved wicking, moisture regain and UV protection; which makes the finished fabric to be suitable for use as medical textiles in wound dressings and for healing abrasive skin injuries in patients suffering from skin diseases [42]. Furthermore, durable coating of sericin on polyester by using glutaraldehyde as crosslinking agent was developed by pretreatment of polyester with alkali (sodium hydroxide) to create carboxylic groups on its surface due to the saponification of ester linkage [43].

In an ongoing project, a team of researchers at the Textile Research Division of the National Research Center in Egypt is using sericin in chemical modifications of some fabrics, to enhance their performances attributes. In this project, sericin is utilized in modification of selected textile substrates; namely wool, viscose, polyester, and polyamide fabrics. The preliminary results of these investigations showed that, sericintreated wool and viscose fabrics led to enhance their microbial resistance. On the other hand, treatment of polyester fabrics with sericin resulted in improving their moisture regain and reducing electrostatic charge. Furthermore, polyamide fabrics treated with sericin exhibited better resistance to the deteriorative action of UV rays. The dyeability of the said sericin-treated fabrics using acid or basic dyes was also upgraded.

\section{Casein}

Casein, as inexpensive and readily available phosphoproteins, has various numbers of good properties including, non-toxicity, high solution viscosity, high thermal stability and the ability to melt that make it to be used widely in food ingredients, pharmaceutical products and as a 
binding agent in industrial products like glue, paint and paper.

\section{Treatment of textile by casein}

In the textile filed, casein was used as a surface-coating material for improving antifelting properties and tensile strength of wool fabric [44].

Because it contains many polar groups, such as $-\mathrm{COOH},-\mathrm{NH}_{2}$, and -OH groups, which contribute to its hydrophilicity and reactivity, casein boosts in the world as a natural polymer for improving the characteristic of synthetic fibers. Where, it has been reported that the hygroscopicity and mechanical properties of acrylic fiber was improved by grafting of casein onto the synthetic acrylic fiber [45].

Recently, casein was considered as an ecofriendly grafting agent for enhancing the strength and stability of muga silk fiber which is affected during the industrial degumming process [46].

\section{Gelatin}

In recent years, textile materials with special applications in the cosmetic field have been developed. So, a new terminology called 'cosmetic textiles' has been inserted in the textile industry and these products are currently available in the markets. Recent study found that, gelatin microcapsules containing vitamin $\mathrm{C}$ were successfully grafted into cotton fabric for development of cosmetic textiles [47].

\section{Utilization of Proteinic Biopolymer in Coloration of Textiles}

\section{Application of keratin in coloration of textile}

There was a great scope for enhancement the dyeability of cotton fabrics with reduction of salt usage in reactive dyeing process by using keratin by-products [48]. Keratin hydrolysate $(\mathrm{KH})$ was extracted from wool fibrous waste and used for medications of cotton fabric. The results of this study showed that, the dyeability of $\mathrm{KH}$ treated cotton fabric with reactive dye was improved without addition of any salt which leads to environmental pollution [49].

In our labs, keratin extracted from cheap coarse Egyptian wool was used for treatment of wool fabric in presence of a crosslinking agent, where it was found that the treated fabric exhibited complete exhaustion for acid and reactive dyes at room temperature within 20 minute [50].
Keratin powder, obtained from different industrial wastes, was utilized in preparation of acrylic/keratin composite. The obtained film exhibited high dyeability towards both acid and reactive dyes even at relatively low dyeing temperatures [51]. So, the prepared acrylic/ keratin films was found to be a successful in the manufacture of plastics and adhesives as well as in dye removal by virtue of the hydrophilicity imparted by the keratin macromolecules.

Currently, in Textile Research Division, nano-keratin powder was prepared from cheap renewable natural resources; namely coarse Egyptian wool or feather. The obtained keratin was utilized as a binder in pigment printing of polyester, poly acrylic, viscose, viscose/polyester, and viscose/poly acrylic fabric, to replace the commercially available produced binder which is highly expensive and environmentally unfriendly. Results of this study showed that the nano-keratin based binder gives almost the same colour strength and fastness properties as the commercial binder with improved stiffness of the printed samples relative to that printed with commercial one.

Application of sericin in coloration of textile

It has been reported that, the dyeability of sericin treated cotton fibers by acid dyes was enhanced along with high moisture absorption and antistatic properties [52].

The grafting of sericin onto plasma pre-treated polyester woven fabric was developed to improve the dyeability of the treated fabric by acid and reactive dyes $[53,54]$

Recently, sericin was applied for treatment of polyester fabric to improve its multifunctional properties and enhance its dyeability with basic dyes [55].

Sericin was also found to be effective in enhancing the printability of wool fabrics with acidic, reactive, and basic dyes and similar results were also encountered when sericin was added to the printing paste [56].

\section{Application of soybean and wheat gluten in coloration of textile}

In a different study, soybean and wheat gluten (WG) were applied as pigment printing binder for cotton and cotton/polyester blend fabrics with excellent fastness to light, washing and to acid and alkaline perspiration $[57,58]$. 


\section{Regenerated proteinic fiber and composites}

The utilization of proteinic biopolymer obtained from different resources in the formation of fiber or composite that to be applicable for different purposes will be highlighted within the following sub-sections.

\section{Regenerated keratin fibers and composites}

The conversion of keratin-based wastes into valuable materials was studied extensively by many workers [59-61]. It has been reported that keratinous waste was ground into powders for further processing, settled into films and lightweight composites [62], and finally chemically modified into thermoplastics and adsorbents $[63,64]$.

S-sulfo keratin powder was combined with poly vinyl alcohol (PVA) to get keratin-PVA blend fiber, via wet spinning, with excellent mechanical properties and used as absorbents for heavy metal ions and formaldehyde gas [65].

Due to its low molecular weight and brittle property, keratin is difficult to electrospun into nanofibers; so keratin was fabricated to nanofibrous mats through the combination with other natural or synthetic Polymers for biomedical applications [66].

Keratin was blended with poly (ethylene oxide) for electrospinning which applied as alternative templates for tissue regeneration [67]. Keratin, extracted from coarse wool, was blended with poly vinyl alcohol (PVA), and then electrospun into nano-fiber mats [68].

Recently, keratinium thiocyanate complex was prepared and used for detection of very low concentrations of iron III ions in domestic water [69]. The chemistry of this process is summarized in the following scheme:

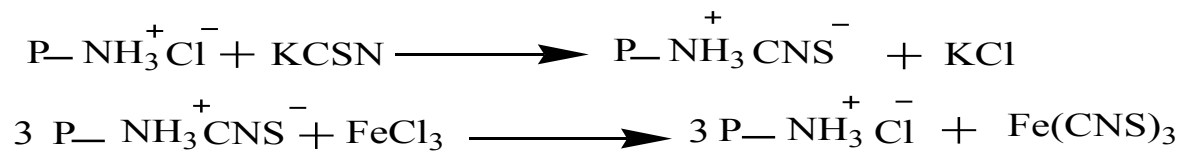

(Red Colour)

Regenerated sericin fibers and composites

Due to its hydrophilicity, which maintains a moist environment and absorbs excess exudates from wounds, sericin was found to possess wound healing property. Thus, sericin was used as wound healing covering material in the form of films and membranes [70] or in the hydrogel and porous scaffolds matrices form [71].

Silk fibroin/silk sericin blend was doped for wet-spinning process, using 98\% formic acid as solvent. This composite material was developed to improve the structure and mechanical property of the regenerated silk by sericin [72]. In a similar research, sericin enhanced the electrospinnability of the regenerated silk fibroin blend to produce high-quality regenerated silk materials used in medical field [73].

In a recent investigation, sericin composite with starch and potassium iodide was prepared and used for detection of free chlorine in industrial and household water [74].

\section{Casein fiber}

Casein fibers were commercially produced in various countries with different trade names such as Aralac and Caslen (U.S.A), Lactofil (Holland), Cargan (Belgium), Tiolan (Germany), Silkool (Japan) and Fibrolane (England) [75].

The fibers were produced by using alkaline solutions and coagulated using sulphuric acid and sodiumsulfate and later crosslinked with aluminum sulfate and formaldehyde. Moreover, regenerated protein fibers developed from casein using alkaline solutions and crosslinked with citric acid [75].

\section{Soybean fibers}

The soybean protein fibres are usually crimped has a white to light tan colour with high resiliency, warmth and soft feel.

Due to their low tensile strength, soybean protein fibres were used predominantly in blends with wool, cotton or synthetic fibres in woven and knitted fabrics for apparel and in upholstery also in cars [76].

Soybean proteins are applied for food and feed and in many industries as adhesives, emulsions, cleansing materials, pharmaceuticals, 
inks, plastics and also textile fibres. After the extraction of oils and other fatty substances, raw material for spinning textile fibres was obtained from soybean [76].

Pure soybean protein fibres (SPF) were developed from the mid-twentieth century by the Japanese [77], where they were produced in Japan under the name Silkool.

Recently, China has been specialized in the research and development new-type textile materials from SPF [78]. Where, SPF resembles in their softness and shininess to silk and cashmere, so producers market them as "artificial cashmere", "vegetable cashmere" or "soy silk" fibres to partially reduce the needs for natural silk and cashmere fibres. Additionally, SPF fibres are promoted on the market as biocompatible and health giving with natural antibacterial properties [79].

\section{Collagen fibers}

Collagen has been broadly used in cosmetic surgery, as a healing help for burns, reconstruction of bone and a wide variety of dental, orthopedic, and surgical purposes [80].

Due to its beneficial role in tissue Engineering, collagen fibres have been developed by wet spinning [81 -83].

As most studies described the fabrication of single fibers, there was little and unsatisfying work on the production of multi-filament collagen yarns that may be used for textile manufacturing [84].

From the materials' engineering point of view, collagen single fibers were comprised up to six fibers and could be suitable for processing the collagen yarns on textile machinery [85].

\section{Gelatin fibers}

Gelatin is a natural biopolymer that is prepared by partial hydrolysis of collagens. Because of its biocompatibility, biodegradability and bioactivity [86]; gelatin was widely used in medical products, such as wound dressings, drug delivery systems, nerves scaffold [87], etc.

Gelatin fiber, which applied for biomedical purposes was prepared using a wet spinning method with a lithium (or calcium) chloride-N, $\mathrm{N}$-dimethylacetamide (DMAc) system using methanol as coagulating bath [88].

In other studies, electro-spun gelatin was fabricated for use in tissue engineering and biomedical applications [89, 90]. Recently, dry spinning was also applied for preparation of gelatin fibers to avoid any toxic organic solvents [91].

\section{Gluten fibers}

Wheat gluten is cheap, abundant, and renewable source for manufacture of films that could be used in food packaging [92] or producing protein fibers [93]. Wheat gluten is suitable for fibers formation due to its good stability to water, heat and excellent elasticity properties [94].

Wheat gluten fibers with mechanical properties similar to those of wool were utilized for biomedical applications such as sutures, implants, scaffolds, and matrices for drug delivery [95].

Electrospinning of commercial wheat protein into nonwoven mats of wheat gluten ribbons and fibers was developed for biomedical purposes [96].

\section{Corn Zein fibers}

Zein, a biodegradable and biocompatible material, has different application including biodegradable plastics, fibers, adhesives, ceramics, inks, cosmetics, textiles and chewing gum [97] and as coating agent in pharmaceutical and food applications.

The relative hydrophobicity of zein makes it to be suitable to form films and filaments. The most successful applications of zein-based biodegradable materials in the pharmaceutical and food industries are as fibers which then designs in a coating form [98].

In another study, a less environmentally aggressive method for producing zein fibers to be used in textile fibers has been reported [99].

In the last years, applications of nanofibers made of zein and zein-based materials in biomaterial fields as scaffolds in tissue engineering or as drug carriers have been proposed [100 101].

Extraction of proteinic biopolymers from natural fibers

Keratin and sericin are considered to be proteinic biopolymers that emitted to the environment as by-products during textile processing. Consequently, several research works have been achieved to extract and recover these biopolymers from natural fibers for further utilization in the development of textile industries. 


\section{Extraction of Keratin from wool}

A large amount of low-grade wool waste is generated during industrial processes including farm breeding, wool fiber by-products from textile processing, poor-quality raw wools that not suitable for spinning, shearing and weaving processes [102]. Thus, recovery of these cheap protein sources and developing a method for extracting keratin from such wastes has been the main purposes of many studies. The major component of wool is keratin protein (about 95\%) and the consideration for extraction of keratin proteins from wool fibers is the breakage and modification of disulfide bonds.

Different methods have been applied for keratin extraction through partial disruption of the keratin structure, including reduction, oxidation and sulfitolysis, [25,103].

From the environmental point of view, enzymatic hydrolysis was considered as an appropriate method to extract keratin from waste wool fibers with the least harm to the environment $[104,105]$

Recently, combination of enzymatic hydrolysis and a reducing agent was applied for extraction of keratin from wool wastes [106].

In another study, ionic liquids (ILs) have attracted considerable attention and have been used for extraction of keratin from wool [107], but the relatively high price and the difficulty of recyclability of ionic liquid restrict its application.

It has been reported that, ionic liquid method produced the highest protein yield (95\%), followed by sulfitolysis method (89\%), followed by the reduction method $(54 \%)$ and the lowest yield was obtained with the oxidation method (6\%) [108].

Moreover, superheated water, green hydrolysis processes, was proposed for extraction of keratin from wool industry wastes to avoid the use of harmful agents [24, 109].

The proteinic and Man-made Fibres Department of the National Research Centre in Egypt adopted a simple method for extraction of keratin from cheap coarse Egyptian wool. This method is based on dissolution of wool in a mixture of alkali metal hydroxide, swelling agent, and reducing agent under controlled conditions of temperature and time [68].
Currently, the dissolution of wool fibres in L-cysteine was considered as an easy and ecofriendly method to extract wool keratins [110]. We believe that the most appropriate method to extract keratin from wool is carried out using sodium dodecyl sulphate together with urea and meta-bisulphite. Although it is time-consuming, yet this method has the advantage of producing soluble keratin with high molecular weight suitable for many applications [111].

\section{Extraction of sericin from silk}

Sericin is extracted from silk fibroin wall by a process known as degumming. Several methods were performed for degumming of silk, including extraction with water, boiling-off in soap, sodaash [112], ultrasound method [113], degumming with acid [114], enzymatic method [115], plasma method [116] and microwave irradiation [117].

Degumming of silk emits about 50,000 tons of sericin per annum in the world [118].

The emission of sericin into waste water by silk industry leads to contamination of water and environment; therefore several approaches have been developed to recover this protein material from degumming liquor. These methods are based on adsorption, precipitation, coagulation, evaporation, chromatography and ultra- filtration [119]

Ethanol [117], enzymatic hydrolysis [120], quaternized chitosan [121], and membrane filtration were also used to recover sericin from the degumming waste solution [122]. Moreover, calcium chloride was applied to recover sericin directly from soap-alkaline degummed waste solution [123].

Abou El-Kheir et al declared that sericin can be precipitated by adjusting the $\mathrm{pH}$ value of the degumming effluent around the isoelectric point of sericin [124].

\section{Conclusion}

As they have the possibility to reduce cost, energy and materials for next generations beside its distinguished eco-friendly properties; biopolymers would be involved in wide applications in various industries.

Nowadays, biopolymers play important roles in many sectors such as food technology, nanotechnology, chemistry, medicine, agriculture, textile industry, etc. 
Direct extraction of biopolymers from different types of waste streams is considered to be one of the important trends in the production of biopolymers.

Great effort would be directed to find out new applications of proteinic biopolymers from solid waste wastes. This will have positive impact from the economic and environmental points of view.

The use of biopolymer in the textile industry is an exciting and innovative area of research for scientists and researchers alongside textile and polymer engineers. As with all types of biopolymer production processes, the acceptance of biopolymer materials, as usual, in textile industry requires the passage of time.

Being reactive polymers contacting various functional groups, sericin and keratin would be used to impart certain desired properties for natural and synthetic fibres. Currently, extensive work is being conducted in our labs for in-situ finishing of natural or synthetic fibers by using proteinic biopolymer which discards from the different industrial effluent.

\section{References}

1. C. Chassenieux, D. Durand, P. Jyotishkumar and S. Thomas, Biopolymers: State of the art, new challenges, and opportunities. In Handbook of biopolymer-based materials, S. Thomas, D. Durand, C. Chassenieux, P. Jyotishkumar, Eds., Wiley-VCH Verlag GmbH \& Co. KGaA: Wenham, 2013, pp. 1-6.

2. N. Teramoto, Synthetic green polymers from renewable monomers. In A handbook of applied biopolymer technology, K. S. Sharma and A. Mudhoo, Eds., RSC Publishing: Cambridge, 2011, pp. 22-78.

3. J. C. Moore, Synthetic polymers in the marine environment: a rapidly increasing, long-term threat, Environ. Res., 108, (2008) 131.

4. K. Sudesh and T. Iwata, Sustainability of biobased and biodegradable plastics, Clean-Soil Air Water., 36 (2008) 433.

5. O. O. Ige and L. E. Umoru, A. Sunday. Natural Products: "A minefield of biomaterials", ISRN Mater., Sci. 2012(2012) 20.

6. W. Holding, Biodegradable polymer Supply chains: Implications and opportunities for Australian agriculture. Kingston: Australia Rural
Industries Research and Development Corporation (2004).

7. M. Carus, W. Baltus, D. Carrez, H. Kaeb, J. Ravenstijn and S. Zepnik, Market study and database on bio-based polymers in the world, Nova-Institute GmbH: Huerth, 7 (2013) 1.

8. D. Voet, G. Voet and W. Pratt, Fundamentals of biochemistry: Life at the molecular level. John Wiley \& Sons: Hoboken, 2nd Edn, 2006.

9. A. S. Sanchez-Vazquez, C. H. Hailes and G. R. Evans, Hydrophobic polymers from food waste: Resources and synthesis, Polym. Rev., 53 (2013) 627.

10. S. A. Herrmann, J. Nickel and U. Riedel, Construction materials based upon biologically renewable resources from components to finished parts, Polym. Degrad. Stabil., 59(1998) 251.

11. K. K. Teresa and B. Justyna, Biodegradation of keratin waste: Theory and practical aspects. Waste Manage., 31 (2011)1689.

12. M.Zoccola, A. Aluigiand C. Tonin, Characterization of keratin biomass from butchery and wool industry wastes. J. Mol. Struct., 938 (2009) 35.

13. Q. Y. Zhang, Applications of natural silk protein sericin in biomaterials, Biotechnol Adv., 20 (2002) 91.

14. R. Jenness, L. B. Larson, L. T. McMeekin, M. A. Swanson, H. C. Whitnah and M. R. Whitney, Nomenclature of the proteins of bovine milk J. Dairy Sci. 39 (1956). 536.

15. K. M. Gordon and A. R. Hahn, Collagens. Cell. Tissue Res., 339 (2010)247.

16. A. A. Mariod and F. H. Adam, Review: Gelatin, source, extraction and industrial applications. Acta Sci. Pol. Technol. Aliment., 12 (2013) 135.

17. B. H. Krishnan, S. S. Natarajan, A. A. Mahmoud and L. R. Nelson, Identification of glycinin and beta-conglycinin subunits that contribute to increased protein content of high-protein soybean lines, J. Agric. Food Chem., 55 (2007) 1839.

18. R. P. Shewry, S.A. Tatham, J. Forde, H. Kreis and J. B. Miflin, The classification and nomenclature of wheat gluten proteins: A reassessment, J. Cereal. Sci. 4 (1986) 97.

19. J. T. Anderson and P. B. Lamsal, Zein extraction from corn, corn products, and coproducts and modifications for various applications: A review. Cereal Chem., 88 (2011) 159.

J.Text.Color. Polym. Sci., Vol. 15, No.1(2018) 
20. S. A. Herrmann, J. Nickel and U. Riedel, Construction materials based upon biologically renewable resources from components to finished parts. Polym. Degrad. Stabil., 59(1998) 251.

21. Salminen and J. Rintala, Anaerobic digestion of organic solid poultry slaughterhouse waste-a review, Bioresource. Techno., 83 (2002)13.

22. A. S. Sanchez-Vazquez, C. H. Hailes and G. R. Evans, Hydrophobic polymers from food waste: Resources and synthesis, Polym. Rev., 53 (2013) 627.

23. M. Cardamone, J. J. Martin, Keratin coatings for wool: shrinkproofing and nanoparticle delivery, Macromol. Symp., 272 (2008) 161.

24. C. Hu, Q. Zhang and K. Yan, Anti-felting Properties of Wool Fabric Treated with Keratin, Key. Eng. Mater., 671 (2016) 14.

25. J. Jia, J. Yao, J. Liu and Y. Liu, Application of Dissolved Wool Keratin in Anti-pilling Processing, Key Eng. Mater., 671 (2016) 53.

26. N. Reddy, L. Chen, Y. Zhang and Y. Yang, Reducing environmental pollution of the textile industry using keratin as alternative sizing agent to poly (vinyl alcohol), J Clean Prod., 65 (2014) 561.

27. H. El-Sayed, L. El-Gabry, H. S. Ibrahim, A. A. ElSayed, E. M. Abou Taleb, N. S. Ammar, M. Salama, A. Abou El-Kheir, S. Mowafi and M. Abou Taleb, Treatment of Selected Man-made Fabrics with Biopolymers and their Utilization in Removal of Copper II Cations from Industrial Wastewater, The $6^{\text {th }}$ Aachen-Dresden International Conference, November 26-27, 2015 (www.aachen-dresden-itc.de).

28. J. R. Patel, and K. M. Modasiya, Sericinpharmaceutical applications. IJRPBS., 2 (2011) 913.

29. R. Voegeli, J. Meier, and R. Blust, Sericin silk protein: Unique structure and properties. Cosmetics Toiletries., 108(1993) 101.

30. J. Cortez, A. Anghieri, R. Bonner, M. Griffin and G. Freddi, Transglutaminase mediated grafting of silk proteins onto wool fabrics leading to improved physical and mechanical properties. Enzyme. Microb. Tech., 40 (2007) 1698.

31. B. I. Khalifa, N. Ladhari, and M. Tuoay, Application of sericin to modify textile supports,J. Text. Inst., 103 (2012) 370.

32. O. G. Allam , H. El-Sayed, A. Kantouch and K. Haggag, Use of sericin in feltproofing of wool, J. Natural. Fibers., 6 (2009) 14.
33. A. Kongdee, T. Bechtold and L. Teufel, Modification of Cellulose Fiber with Silk Sericin, J. Appl. Polym. Sci., 96 (2005)1421.

34. T. Xing, J. Liu, G. Chen, J. Sheng, D. Sun and Z. Chen, Study on Finishing of Cotton Fabric by Sericin and Its Properties, Adv. Mater. Res., 175 (2011) 624

35. R. Rajendran, C. Balakumar, R. Sivakumar, T. Amruta, and N. Devaki, Extraction and application of natural silk protein sericin from Bombyxmori as antimicrobial finish for cotton fabrics, J. Text. Inst., 103(2012) 458.

36. S. Doakhana, M. Montazerb, A. Rashidi, R. Moniri, M. B. Moghadamd, Influence of sericin/ $\mathrm{TiO} 2$ nanocomposite on cotton fabric: Part 1 Enhanced antibacterial effect, Carbohyd. Polym., 94 (2013) 737.

37. X. Yue, H. Lin, T. Yan, D. Zhang, H. Lin, and Y. Chen. Synthesis of Silver Nanoparticles with Sericin and Functional Finishing to Cotton Fabrics, Fibers. Polym., 15 (2014) 716.

38. L. M. Gulrajani, P. K. Brahma, S. P. Kumar and R. Purwar, Application of silk sericin to polyester fabric. J. Appl. Polym. Sci., 109 (2008) 314.

39. S. Sarovart, B. Sudatis, P. Meesilpa, P. B. Grady and R. Magaraphan, the use of sericin as an antioxidant and antimicrobial for polluted air treatment, Rev. Adv. Mater Sci.,5 (2003) 193.

40. Z. P. Jin, T. Igaeashi and T. Hori, Application of silk sericin for finishing of polyester and nylon fabrics, Sen'I Kogyo Kenkyu Kyokai Hokoku.,3(1993), 44

41. B. N. Prakash, D. Ravikumar, G. Thimmareddy and R. Subrata, Studies on crosslinking of sericin on polyster fabric, Man-made Textiles in India., March (2010) 96.

42. D. Gupta, H. Chaudhary and C. Gupta, Sericinbased polyester textile for medical applications, J. Text. Inst.,106 (2015) 366.

43. S. Natarajan, J. J. Moses, S. Natarajan and J. J. Moses, Surface modification of polyester fabric using poly vinyl alcohol in alkaline medium, Indian. J. Fibre. Text. Res., 37(2012) 287.

44. L. Cui, X. Fan, P. Wang, Q. Wang and G. $\mathrm{Fu}, \quad$ Casein and transglutaminase-mediated modification of wool surface, Eng. Life Sci., 11 (2011), 201. 
45. Z. Jia, S. Du, and G. Tian, Surface Modification of Acrylic Fiber by Grafting of Casein, J. Macromol. Sci. Pure., 44 (2007) 299.

46. M. Choudhury, B. alukdar, N. N. Dass, K. C. Baruah and D. Devi, Impact of BSA and casein on chemical modification of muga silk fiber, J. Text. Inst., 107 (2016), 346.

47. S. Y. Cheng, M. C. Yuen, C. W. Kan, K. K. Cheuk, C. H. Chui, and K. H.G Lam, Cosmetic textiles with biological benefits: Gelatin microcapsules containing Vitamin C, Int. J. Mol. Med., 24 (2009) 411.

48. R. Karthikeyan, S. Balaji and P. K. Sehgal, Industrial applications of keratin - a review. J. Sci. Ind. Res., 66(2007)710.

49. N. Arivithamani, S. A. Mary, M. S. Kumar and V. R. Dev, Keratin hydrolysate as an exhausting agent in textile reactive dyeing process, Clean. Techn. Environ. Policy.,16 (2014) 1207.

50. A. Kantouch, O. Allam, L. El-Gabry, H. ElSayed, Effect of pretreatment of wool fabric with keratin on its dyeability with acid and reactive dyes, Indian. J. Fibre. Text. Res., 37 (2012) 157.

51. L. El-Gabry, A. Abou El-Kheir, M. Salama, S. Mowafi and H. El-Sayed, Acrylic/Keratin Composite of Enhanced Dyeability Towards Cationic and Anionic Dyes, Color. Technol., 132 (2016) 83.

52. A. Kongdee and N. Chinthawan, Modification of Cotton Fibers with Sericin Using NonFormaldehyde Released Crosslinking Agents, RJTA., 11 (2007) 18.

53. D. Kamalraj and V. Subramaniam, Application of Sericin on Polyester Fabric, Appl. Mechan. Mater., 813-814 (2015) 156.

54. I. B. Khalifa and N. Ladhari, Enhancement of Poly (Ethylene Terephtalate) Adsorption Using a Green Process, IJNTR., 2 (2016) 49.

55. H. Chaudhary, D. Gupta and C. Gupta, Multifunctional dyeing and finishing of polyester with Sericin and Basic dyes, J. Text. Inst., 108 (2017) 314.

56. K Haggag, F. Kantouch, O. G Allam, H El-Sayed, Improving Printability of Wool Fabrics Using Sericin”, J. Natural. Fibers, 6 (2009)236.

57. F. A Kantouch, Z. M Mahmoud, E. M Khalil, M. H Helal and K. Haggag, Evaluating modified soy protein isolate as textile printing binder, Egyp. J. Chem., 50 (2007) 185.

58. L.E. Hamilton and A. Chiweshe, Textile pigment printing binders prepared by modifying wheat gluten with methyl acrylate", Starch -Starke, 50 (1998) 213.

59. B. Tang, X. Zhou, T. Zeng, X. Lin, J. Zhou, Y. Ye and X. Wang, In Situ Synthesis of Gold Nanoparticles on Wool Powder and Their Catalytic Application, Materials., 10(2017) 295.

60. G. Wen, R. Naik, P. Cookson, S. Smith, X. Liu and X. Wang, Wool powders used as sorbents to remove $\mathrm{Co} 2+$ ions from aqueous solution. Powder. Technol., 197(2010)235.

61. R. Rajkhowa, Q. Zhou, T. Tsuzuki, A. Morton, $\mathrm{X}$. Wang, Ultrafine wool powders and their bulk properties. Powder Technol., 224(2012):183-188.

62. S. Huda and Y. Yang Feather Fiber Reinforced Light-Weight Composites with Good Acoustic Properties. J. Polym. Environ., 17(2009)131.

63. C. Hu, N. Reddy, K. Yan and Y. Yang, Acetylation of chicken feathers for thermoplastic applications. J. Agri. Food. Chem., 59 (2011) 10517.

64. P. Sun, T. Z Liu and W. Z. Liu, Chemically Modified Chicken Feather as Sorbent for Removing Toxic Chromium (VI) Ions. Ind. Eng. Chem. Res., 48(2009) 6882.

65. K. Katoh, M. Shibayama, T. Tanabe and K. Yamauchi, Preparation and Properties of KeratinPoly (vinyl alcohol) Blend Fiber, J. Appl. Polym. Sci., 91(2004)756.

66. G. J. Rouse and E. M.Van Dyke, A review of keratin-based biomaterials for biomedical applications. Materials.,3(2010) 999.

67. T. Sow, Y. S. Lui and K. W. Ng, Electrospun human keratin matrices as templates for tissue regeneration, Nanomedicine., 8 (2013) 531.

68. S. Mowafi, M. Abou Taleb, A. Abou El-Kheir and H. El-Sayed, Electrospun Keratin/Polyvinyl Alcohol Regenerated Fibers Part 1: Preliminary Study, J. Natural Fibers., 10(2013) 341.

69. S. Mowafi, M. Abou Taleb and H. El-Sayed, Towards analytical stripes for detection of Iron III cations in domestic water using proteinic biopolymers, J. Clean. Prod., 202 (2018) 45.

70. P. Aramwit, T. Siritientong and T. Srichana, Potential applications of silk sericin, a natural

J.Text.Color. Polym. Sci., Vol. 15, No.1(2018) 
protein from textile industry by-products, Waste Manag. Res., 72 (2011) 3189.

71. P. Aramwit, J. Ratanavaraporn and S. Ekgasit, A green salt-leaching technique to produce sericin/ PVA/glycerin scaffolds with distinguished characteristics for wound-dressing applications. J. Biomed. Mater. Res. B Appl. Biomater., 103 (2015) 915 .

72. C.S. Ki, J.W. Kim, H.J. Oh, K.H. Lee, and Y.H. Park: The effect of residual silk sericin on the structure and mechanical property of regenerated silk filament. Int. J. Biol. Macromol., 41(2007) 346.

73. Y. Hang, Y. Zhang, Y. Jin, H. Shao and X. Hu, Preparation and characterization of electrospun silk fibroin/sericin blend fibers, J. Mater. Res., 26 (2011) 2931.

74. H. El-Sayed, A. Abou El-Kheir, M. Abou Taleb, and S. Mowafi, Utilization of keratin and sericin in easy detection of free chlorine in water, under publication in Environ. Sci. Pollut. Res., (2018).

75. Y. Yanga and N. Reddy, Properties and potential medical applications of regenerated casein fibers crosslinked with citric acid, Int. J. Biol. Macromol., 51 (2012) 37.

76. T. Rijavec and Ž. Zupin, Soybean Protein Fibres (SPF) In: Recent Trends for Enhancing the Diversity and Quality of Soybean Products, chapter 23 Edited by Prof. Dora Krezhova, 2011, pp 504-522.

77. T. Kajita and R.Inoue, Process for manufacturing artificial fiber from protein contained in soya bean, (1940)US Patent 2,191,194.

78. Anon, Innovations China develops soyabean fibre, Text. Magazine, 30(2003) 4.

79. L. Yi-you, the soybean protein fibre - a healthy \& comfortable fibre for the 21 st century, Fibres. Text. Eastern Europe., 12(2004) 8.

80. G. Cunniffe and F. O'Brien, Collagen scaffolds for orthopedic regenerative medicine, J. Minerals. Metals. Material. Society., 63 (2011) 66.

81. R. Parenteau-Bareil, R. Gauvin and F. Berthod, Collagen-based bio-materials for tissue engineering applications. Materials., 3 (2010) 1863.

82. S. J. Kew, J.H. Gwynne, D. Enea, M. Abu-Rub, A. Pandit, D. Zeugolis, Regeneration and repair of tendon and ligament tissue using collagen fibre biomaterials, Acta Biomater., 7 (2011) 3237.

83. S. J. Kew, J.H. Gwynne, D. Enea, R. Brookes, N. Rushton and S. M. Best, Synthetic collagen fascicles for the regeneration of tendon tissue. Acta Biomater. 8 (2012) 3723.

84. M. Meyer, H. Baltzer and K. Schwikal, Collagen fibres by thermoplastic and wet spinning. Mater Sci Eng C Mater Biol Appl., 30 (2010) 1266.

85. J. H. Shepherd, S. Ghose, S. J. Kew, A. Moavenian, S. M. Best, R. E. Cameron. Effect of fiber crosslinking on collagen-fiber reinforced collagen-chondroitin-6-sulfate materials for regenerating load-bearing soft tissues. J Biomed Mater Res Part A., 101 (2013) 176.

86. Y. Wan, Y. Wang,G. Cheng,K. Yao, Preparation and characterization of gelatin gel with a gradient structure. Polym. International., 49(2000) 1600.

87. X.K Li, S. X Cai and B.Liu, Characteristics of PLGA-gelatin complex as potential artificial nerve scaffold. Colloid. Surface B., 57(2007) 198.

88. S.Tokura, H. Tamura and N.Itoh, Gelatin Fiber and Process for Producing the Same. (2005) Patent WO2005,054,553.

89. Z.Y.Zhang, J.Venugopal, Z. M, Huang, Crosslinking of the electrospun gelatin nanofibers. Polymer., 47(2006) 2911.

90. T. Nguyen and B. Lee, Fabrication and characterization of cross-linked gelatin electrospun nano-fibers.J. Biomed. Sci. Eng., 3 (2010) 1117.

91. T. Chaochai, Y. Imai, T. Furuike and H. Tamura, Preparation and Properties of Gelatin Fibers Fabricated by Dry Spinning, Fibers., 4 (2016) 2.

92. P. H. Munoz, A. Kanavouras, P. K. Ng and R. Gavara, Development and Characterization of Biodegradable Films Made from Wheat Gluten Protein Fractions, J. Agric. Food. Chem., 51 (2003) 7647.

93. L. D. Woerdeman, S. W. Veraverbeke, S. R. Pamas, D. Johnson, A. J. Delcour, I. Verpoest and G. J. Plummer, Designing New Materials from Wheat Protein Biomacromolecules., 5 (2004) 1262.

94. A. J. Bietz and L. G. Lookhart, Properties and nonfood potential of gluten, Cereal. Food. World., 41 (1996) 377. 
95. N. Reddy and Y. Yang, Novel Protein Fibers from Wheat Gluten, Biomacromolecules., 8 (2007) 638.

96. D. L. Woerdeman, P. Ye, S. Shenoy, R. S. Parnas, G. E. Wnek, and O. Trofimova, Electrospun Fibers from Wheat Protein: Investigation of the Interplay between Molecular Structure and the Fluid Dynamics of the Electrospinning Process, Biomacromolecules., 6 (2005), 707.

97. R. Shukla and M. Cheryan, Zein: The industrial protein from corn. Ind. Crops Prod., 13 (2001) 171.

98. Y. Wang, F. Lopes, P. Geil and W. G. Padua, Effects of processing on the structure of zein/ oleic acid films investigated by X-ray diffraction. Macromol. Biosci., 5 (2005), 1200.

99. C. W. Uy, Zein Corn-Protein Fibre Production for Use in Clothing Fabrics involves Dry Spinning from a Volatile Solvent System, and Avoids Use of Environmentally Hazardous Alkaline Solutions and Acid Coagulating Baths. US5750064-A, (1998).

100. D. Brahatheeswaran, A. Mathew, G. R. Aswathy, Y. Nagaoka, K. Venugopal, Y. Yoshida, T. Maekawa and D. Sakthikumar, Hybrid fluorescent curcumin loaded zein electrospun nanofibrous scaffold for biomedical applications. Biomed. Mater. 7 (2012) 45001.

101. S. Wongsasulak, S. Pathumban, T. Yoovidhya, Effect of entrapped alpha-tocopherol on mucoadhesivity and evaluation of the release, degradation, and swelling characteristics of zeinchitosan composite electrospun fibers. J. Food Eng.,120 (2014) 110.

102. A. Aluigi, C. Vineis, A. Ceria and C. Tonin, Composite Biomaterials From Fiber Wastes: Characterization of Wool-Cellulose Acetate Blends. Composites Part A Appl. Sci., 39 (2008) 126.

103. M. J. Cardamone, Investigating the Microstructure of Keratin extracted from wool: peptide sequence (MALDI-TOF/TOF) and protein conformation (FTIR), J. Mol. Struct., 969 (2010) 97.

104. R. Gupta and P. Ramnani, Microbial keratinases and their prospective applications: An Overview, Appl. Microbiol. Biotechnol., 70 (2006) 21.

105. A. Brandelli, Bacterial Keratinases: Useful enzymes for bioprocessing agro industrial wastes and beyond, Food. Bioprocess, Technol., 1 (2008) 105.
106. N. Eslahi, F. Dadashian and N. H. Nejad, An investigation on keratin extraction from wool and feather waste by enzymatic hydrolysis, Prep. Biochem. Biotech., 43 (2013) 624.

107. A. Ghosh, S. Clerens and S. Deb-Choudhury, Thermal effects of ionic liquid dissolution on the structures and properties of regenerated wool keratin, Polym. Degrad. Stabil., 108 (2014) 108.

108. A. Shavandi, A. A. Bekhit, A. Carne and A. Bekhit, Evaluation of keratin extraction from wool by chemical methods for bio-polymer application, J. Bioact. Compat. Polym., 12 (2016) 163.

109. M. Zoccola, A. Aluigi, A. Patrucco, C. Vineis, F. Forlini, P. Locatelli, M. C. Sacchi and C. Tonin, Microwave-assisted chemical-free hydrolysis of wool keratin, Text. Res. J., 82(2012) 2006.

110. K. Wang, R. Li, J. H. Ma,Y. K. Jiana and J. N. Che, Extracting keratin from wool by using L-cysteine, Green Chem., 18(2016) 476.

111. A. Aluigi, C. Vineis, A. Varesano, G. Mazzuchetti, F. Ferrero and C. Tonin, Structure and properties of keratin/PEO blend nanofibres, Eur. Polym. J., 44 (2008) 2465.

112. S. Chopra and L. Gulrajani, Comparative evaluation of various methods of degumming silk, Indian. J. Fibre. Text. Res., 19 (1994) 76.

113. M. Mahmoodi, M. Arami, F. Mazaheri and S. Rahimi, Degradation of sericin (degumming) of Persian silk by ultrasound and enzymes as a cleaner and environmentally friendly process, J. Clean. Product., 18 (2010)146.

114. M. L. Gulrajani and A Chatterjee, Degumming of silk with oxalic acid, Indian. J. Fibre. Text. Res., 17 (1992) 39.

115. V. Krishnaveni and G. RajKumar, Study on effect of proteolytic enzyme degumming on dyeing of silk, Colourage., 57 (2010) 61.

116. J. J. Long, H. W. Wang, T. Q Lu, R. C. Tang and Y.W. Zhu, Application of Low-Pressure Plasma Pretreatment in Silk Fabric Degumming Process. Plasma Chem. Plasma. P., 28 (2008) 701.

117. N. M. Mahmoodi, F. Moghimi, M. Arami, F. Mazaheri, Silk degumming using microwave irradiation as an environmentally friendly surface modification method, Fibers. Polymers., 11 (2010) 234.

J.Text.Color. Polym. Sci., Vol. 15, No.1(2018) 
118. K. S. Rajput and M.K. Singh, Sericin - A Unique Biomaterial. IOSR J. Polym. Text. Engineering., 2 (2015) 29.

119. V.R. Silva, M. Ribani, M. L. Gimenes, and A.P. Scheer, High molecular weight sericin obtained by high hemperature and ultrafiltration process, Procedia Engineering., 42 (2012) 8331.

120. J. H. Wu, Z. Wang, S. Y. Xu, Enzymatic production of bioactive peptides from sericin recovered from silk industry wastewater. Proc. Biochem., 43 (2008) 480.

121. J. Lin, L. Wang and L. Wang, Coagulation of sericin protein in silk degumming wastewater using quaternized chitosan. J. Polym. Environ., 20(2012), 858 .

122. P. Vaithanomsat and V. Kitpreechavanich, Sericin separation from silk degumming wastewater. Sep. Purif. Technol., 59(2008) 129.

123. Y. Yang, S. M. Lee, H. S. Lee, and K. H. Lee, Recovery of Silk Sericin from Soap-Alkaline Degumming Solution, Int. J. Indust. Entomol., 27(2013) 203.

124. A. Abou El-Kheir, H. M. Masoud, S. Mowafi, K. Haggag and H. El-Sayed, A Novel Approach towards Simultaneous Degumming and Dyeing of Bombyx mori Silk, Der Pharma Chemica., 8 (2016)10.

(Receive 2/9 /2018; accepted 28/10/2018 ) 


$$
\begin{aligned}
& \text { استخام البوليمرات البروتينية الحيوية: الوضع الراهن وتوقعات المستقبل } \\
& \text { سلوى مو افى، مروى أبو طالب، حسام السيد } \\
& \text { قسم الالياف البروتينية والصناعية، شعبة بحوث الصناعات النسجية، المركز القومى للبحوث }
\end{aligned}
$$

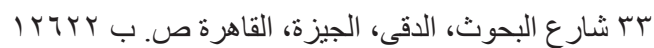

شهلت العقود الثلاثة الخيرة اهتمام متزايد لاى البحاث نحو التلوث البيئى لايجاد منتجات جليدة صحية وأمنة

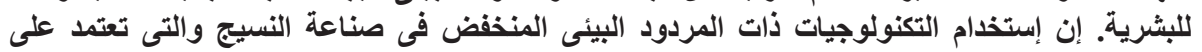
البوليمرات الحيوية المستدامة تقدم طريقة جليدة لتنمية النسيج النثط بيولوجيا" على نطاق واسع.

يهاف هذا البحث الرجعى الى تقديم نظرة عامة عن دور البوليمرات البروتينية الحيوية فى تنمية الصناعات

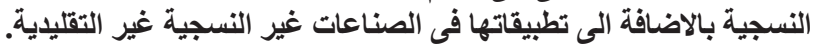

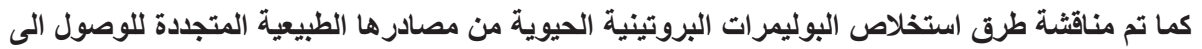
الطرية المناسبة للاستخلاص. 